\title{
Incorporating Extensive Reading into Reading Lessons for the Development of Reading Abilities
}

Pham Thi Thuy*, Duong Thi Thuc

Military Science Academy, Vietnam

How to cite this paper: Thuy, P.T., Thuc, D.T., (2020). Incorporating Extensive Reading into Reading Lessons for the Development of Reading Abilities. The Educational Review, USA, 4(2), 38-44. DOI: 10.26855 /er.2020.02.003

Received: June 5, 2019

Accepted: June 27, 2019

Published: February 13, 2020

Corresponding author: Pham Thi Thuy, Military Science Academy, Vietnam.

Email: thuybinbong8@gmail.com

\begin{abstract}
The study aims at investigating the effects of incorporating extensive reading into reading lessons to enhance students' reading ability and increase their English proficiency on the whole. A quasi-experiment was conducted in two groups of first-year English majors at Military Science Academy (MSA): 16AD1 - the experimental group and 16AD2 - the control group. The main instruments deployed are pre-test and post-test. Also, to ensure the validity and reliability of the study, an introspective interview with three best and three worst students was carried, transcribed and analyzed. The effects of incorporating extensive reading into reading lessons were measured through the T-test based on a pre-test post-test comparison. The data obtained were generalized and analyzed by using percentage, mean, standard deviation, and dependent samples t-test. From the results of the study, some suggestions on practical applications of extensive reading and monitoring students' performance are also made.
\end{abstract}

Keywords

Extensive Reading, Reading Ability, Reading Comprehension

\section{Introduction}

Along with the macro-skills, reading is a crucial factor in second language acquisition as it might help learners partly make extensive use of academic materials written in English. The ultimate goal of reading is comprehension and it allows students to make sense of what the text is about. In order to be successful language learners, it is said to rely on many factors such as teachers, learners, and materials (Smith, 1985). At MSA, Concept and Comments has been recommended and used as a core textbook to teach reading skills to the first-year students as it is supposed to be a rather reliable source to enhance students' reading ability. However, Concept and Comments belongs to commercial textbooks designed for learners all over the world, hence it cannot meet the specific needs of the first-year English majors at MSA. The textbook is generally considered as a tool, and the teacher must know not only how to use it, but also how to adapt it. As far as teaching methodology is concerned, reading comprehension is taught both as part of an integrated skills class and as a separate subject. In both cases, a great deal of attention is paid to intensive reading, which is done in the classroom, and little or none to extensive reading. It is often seen in the reading lessons at MSA that the teachers control the conditions of reading by giving instructions and explaining vocabulary, structure and grammar, teaching reading strategies and checking students' comprehension in the hope to help students learn English, which turns reading into a process of detailed study, memorization, analysis and guessing (Field, 2002). For the reading exercises in the textbook, 
the students often do at home and write the answers in the book and the teacher just goes over them orally with the students, giving feedback, explaining or elaborating here and there. As a result, this passive way of learning is hard to maximize students' reading abilities and their full language potential as it does not make good use of students' autonomy, creativity and time.

Given the limitations of intensive reading, the incorporation of extensive reading into reading lessons seems to be a good choice to expand the teaching and learning options and enable learners to acquire worldwide knowledge beyond the classroom. The benefits of reading extensively have received much attention in the literature, especially among researchers and language teachers. Hedge (2000) states that the biggest benefit extensive reading brings is to expose learners to a large amount of meaningful and interesting second language input. Hedge (2000, p203) mentions that extensive reading offers learners "opportunities to practise reading strategies and developing different types of knowledge". Day and Bamford (1998) believe that extensive reading is an excellent way for learners to gain a communicative command of English, specifically with grammar and vocabulary. Krashen (1993) has concluded that simply allowing students to read more books will result in improved reading.

The above-mentioned reasons have urged the authors to conduct this study entitled "Incorporating Extensive Reading into Reading Lessons for the Development of Reading Abilities". The study is intended to make a contribution to helping the first-year English majors at MSA improve their reading skills.

\section{Literature Review}

Extensive reading is defined in different ways by various language researchers and specialists. For example, Bright and McGregor (1973) use the term to indicate an amount of reading, perhaps 50 books per year (cited in Hedge, p62). Meanwhile, Krashen relates extensive reading to time, perhaps an hour every evening (cited in Hedge, p183). When talking about extensive reading, few language professionals dispute the advantages of extensive reading for developing students' vocabulary, improving autonomy and reading abilities, giving motivation to read more, and other aspects of language skills (e.g., Anderson and Urquhart, 1984; Day \& Bamford, 1998; Grabe \& Stoller, 2001; Smith, 1985). According to Day and Bamford (1998), one great point of extensive reading is that it leads to "reading gain without reading pain" (p.121). Sharing the same point, Siberstein (1994) confirms that through extensive reading, students have good opportunities to be exposed to lexical items that are embedded within natural linguistic applications. This exposure is of great significance to enable language learners to acquire meanings as native speakers do. Since these reading texts are put in certain authentic contexts, they are expected to provide learners with a wide variety of registers, subjects and text types that are at different difficulty levels (Smith, 1988). In short, most of the studies appreciate the benefits of extensive reading as it leads to improved reading skills, greater enjoyment of reading, more positive attitude toward reading and higher possibility of developing a good reading habit. Although the benefits of extensive reading are obvious, in the context of MSA, some students hesitate to accept the practice because it differs considerably from conventional instructions. Some teachers experience difficulties incorporating extensive reading into their classrooms because of inflexible curricula and limited source of references. Specifically, teachers of reading skills have to follow the set timetable, with 2 periods of 90 minutes a week for reading comprehension. In these 2 periods, teachers are expected to cover one assigned reading unit, covering many aspects of learning such as vocabulary, comprehension check, comprehension questions, reading strategy, grammar review, etc. Other teachers, who occasionally bring extensive reading into their classes, do not know how to fully exploit its language learning potential. A great number of studies related to extensive reading have been conducted in a variety of settings. For example, Le Thi Anh Phuong's study (2005) reveals that extensive reading can be seen as a great way to help learners become more autonomous and 
more responsible for their English learning. Sharing the same view, another researcher Nguyen Van Son (2002) unveils that using extensive reading can improve learners' autonomy and develop their reading habit. Meanwhile, Le Thi Huong Lan (2015) claims that extensive reading contributes to motivate students to learn and helps to change their attitude toward language learning in a more progressive way. Generally, most of these studies show positive results of extensive reading such as improved reading skills, positive attitude toward reading, higher autonomy and improved vocabulary and grammar. However, most of these studies were conducted with a limited number of participants and the use of extensive reading to develop reading abilities still gets the major concern of many educators, language teachers and researchers. Therefore, it would be worthwhile to examine the effectiveness of incorporating extensive reading into reading lessons in order to develop reading abilities for the first year English majors at MSA.

\subsection{Research question}

Is the method of teaching reading incorporated with extensive reading more effective than the traditional teaching method in developing reading abilities for the first-year English majors at MSA?

\section{The study}

\subsection{Participants}

The study was carried out with the participation of two groups including 76 first-year English majors at MSA. The students under investigation belong to civilian section (at MSA there are 2 separated sections: military and civilian). As they have finished their first-term and almost the second-term of the first-year at MSA, they can be supposed to be at intermediate level of English proficiency.

\subsection{Instruments}

In this study, the main means of data collection is a pre-test-post-test, which was designed to find out the effects of incorporating extensive reading into reading lessons. Besides, another source of data was gathered from an introspective interview to double-check the effects of incorporating extensive reading into reading lessons. The interview was conducted with three best and three worst students from the experimental group to find out what they had done, thought, and learned in reading lessons incorporated by extensive reading. There were five open-ended questions for the interview, which asked about students' attitude towards extensive reading, their opinions on its benefits, and to what extent this method motivated and encouraged them to read more.

\subsection{Procedures of data collection}

We planned to monitor the progress of the extensive reading program over one semester of the academic year 2016-2017. The pre-test was administered to the experimental group, 16AD1 and the control group, 16AD2 on the first day of the experiment class and post-test was conducted after the experiment finished. Next, one researcher taught the quasi-experimental group (16AD1) by incorporating extensive reading into reading lessons, another researcher applied the traditional teaching method to teach the other group (16AD2). The results of the tests were coded and analyzed for mean of scores and standard derivation of the examination scores.

For the introspective interview, self-reflection form was provided one day after the post-test examination. Specifically, an interview sheet of 6 open-ended questions was developed. The first 5 questions were aimed to gain deep understanding of the participants' viewpoints on extensive reading. Question 6 collected the participants' 
recommendations for the improvement of the application of these reading strategies. Of the 38 participants from the experimental group, the three who achieved the highest scores and the three who achieved the lowest scores were selected for the 6 independently face-to-face interviews. The data gained were recorded, transcribed and analyzed using the interview protocol sheet, which reports on the interviewees' viewpoints on extensive reading as well as their suggestions for improving the strategies.

\section{Findings and Discussions}

\subsection{From the results of T-test}

An independent sample T-test for correlated samples is presented to compare the results of the reading pre-test and post-test performed by the students of the two groups: experimental and control one. This is aimed at finding out the effects of incorporating extensive reading into reading lessons on the development of the students' reading abilities.

Table 1. The mean score of the control group $(\mathrm{N}=38)$

\begin{tabular}{cccc}
\hline Value & Post-test & Pre-test & Post-test - pre-test \\
\hline Mean & 6.43 & 5.25 & 1.18 \\
\hline$\sum \mathrm{x}$ & 244 & 205 & 39 \\
\hline Sum of Squares & 31.58 & 29.37 & 2.21 \\
\hline
\end{tabular}

Table 2. The results of t-value, df of the control group $(\mathrm{N}=38)$

\begin{tabular}{cccc}
\hline Mean post-test - Mean pre-test & t- value & df & one-tailed \\
\hline & & & $<0.0001$ \\
\hline 1.18 & +5.69 & 73.9 & $<$ \\
\hline
\end{tabular}

The result from the above table shows that the mean different between pre-test and post-test was 1.18. Furthermore, its $t$-value is +5.69 , which is validated by the $\mathrm{p}$. value $(<0.0001)$. Hence, it can be concluded from these figures that there is a slight difference between the post-test and pre-test. In other words, the class who did not apply the extensive reading still made some progress in their reading skills. The highest difference between the pre-test and post-test of the whole class is 2.0, which is ranked the first in the whole class between the pre-test and post-test of the control class. The reason for the least improvement among students may be the teaching method and the students' passive recipient.

Table 3. The mean score of the experimental group $(\mathrm{N}=38)$

\begin{tabular}{cccc}
\hline Value & Post-test & Pre-test & Post-test - pre-test \\
\hline Mean & 6.93 & 4.72 & 2.21 \\
\hline$\sum \mathrm{x}$ & 265 & 175 & 90 \\
\hline Sum of Squares & 32.08 & 31.84 & 0.24 \\
\hline
\end{tabular}

Table 4. The results of t-value, df of the experimental group $(\mathrm{N}=38)$

\begin{tabular}{llll}
\hline Mean post-test - Mean pre-test & t- value & Df & one-tailed \\
\hline & & & $<0.0001$ \\
\hline 2.21 & +10.73 & 74 & \\
\hline
\end{tabular}

As can be seen from the table, the mean of the pre-test was only 4.72; though the students' level when taking part in the experiment was much lower than that of the control group, the mean difference between the pre-test and post-test is 
2.21 , which is much higher than that of the control class (only 1.18). Moreover, t-value is +10.73 , bigger than that of the control class. These values are backed by the $p$. value (only $<0.0001$ ). Generally, the descriptive statistics of the two tests above could lead us to a better insight into the performance of the students before and after the quasi-experiment.

Clearly, the result of the statistical analysis indicates that there is a significant effect in the scores between two groups when extensive reading was incorporated into reading lessons for the experimental group. In this group, the highest difference between the pre-test and post-test is 3.0.

Table 5. A comparison result of the reading pre-test and post-test performance of the control class (C) with the experimental class (E)

\begin{tabular}{cccc}
\hline & Means & T-value \\
\hline $\begin{array}{c}\text { Pretest } \\
\text { E - C }\end{array}$ & $\begin{array}{c}\text { Posttest } \\
\text { E -C }\end{array}$ & Experimental group - Control group & Experimental group - Control group \\
\hline-0.53 & 0.5 & -0.014 & 4.68 \\
\hline
\end{tabular}

The result of the statistical analysis indicates that there is a significant variance in scores between two groups 16AD1 (experimental group) and 16AD2 (control group) when students of experimental group were applied extensive reading in their reading lessons.

In fact, the starting point of language proficiency of the two groups is of rather difference when the control group performed better than the experimental one in the pre-test. After being taught with the application of extensive reading, the experimental group gained much better results than the control group. In other words, the t-test shows that there is a significant difference between the experimental and control group when the experimental group was treated with extensive reading in their reading lessons.

Based on the results collected from the t-test, it is possible to conclude that: Incorporating extensive reading into reading lessons can enhance students' reading ability and increase their English proficiency on the whole.

\subsection{From the Introspective Interview}

From the self-reflection from, the incorporation of extensive reading into reading lessons revealed the following benefits: First, probably the most cited benefit of extensive reading was that it extended and sustained students' vocabulary growth. It is known that vocabulary is not learned by a single exposure. However, if students read extensively they are much more likely to pick up vocabulary in a variety of contexts. Second, students became more motivated to read. It was highly motivating for students to discover that they could read in English and that they enjoyed it. This can also help to boost their confidence and self-esteem as language learners. Next, the participants claimed that extensive reading developed their autonomy because they could read anywhere, at any time, and reading extensively helped them become more autonomous learners. Finally, during these experimental lessons, the mutual interactions and understanding between the teacher and the students and among the students themselves were boosted and accordingly this led to a friendly and cooperative learning environment.

However, there seem to have some difficulties facing these students while reading, mainly due to vocabulary barrier which hinders their understanding. Moreover, some claimed that they came across with uninteresting texts.

\section{Conclusions and Implications}

In the study, some relevant literature on theories of extensive reading have been taken into account in order to elaborate the benefits of incorporating extensive reading into reading lessons to develop students' reading abilities. The study was conducted on two classes of the first-year English majors with a total of 76 students. A T-test was run to find out the 
difference between the pre-test and post-test mean scores of the two groups: the experiment and the control group. The students' self-reflection form was also utilized to support the results of the study. Optimistically, most of the interviewees support the use of extensive reading as one way to make up for the insufficient areas of intensive reading as well as to expose learners to as many kinds of materials as possible. From the results of the study, the authors have suggested some practical applications of extensive reading to the existing Reading Course.

Extensive reading appears to be very effective when incorporated into a Reading Comprehension Course for first-year English majors at MSA, as shown in the feedback and results presented above. It is noted that extensive reading should ensure that students read a great number of texts at their linguistic competence in terms of vocabulary and grammar, on topic of their interests, without tests, assessments or homework (Field, 2002). However, how can teachers orient students to the goals of the course, give them constant motivation and keep track of what they have read? With extensive reading, the following activities can be alternatively applied to give motivation and informal assessment on the students' performance made by the teacher during the course.

Firstly, the teacher can ask students to keep the reading journal, in which students write the title, author, level, date they started, and date they finished each reader. This allows the students and the teacher to come to an agreement to see how much has been read over a certain period of time. After reading, the students write a summary and a brief comment on the book. The teacher collects the reading notebooks once a week, reads them, and comments on the progress which students have made. It is enjoyable for teachers to read students' reaction reports because they can get an insight into their students' thoughts and feelings. If teachers respond to students' reaction reports with their own comments or questions, the reports partly help to establish a friendly learning environment with great mutual understanding between the teacher and the student. Secondly, the teacher asks students to present an oral report on each book they read to the class or to a selected group. Students are encouraged to select their favorite works and present in such a way to make others want to read it. The report should include the title and author, a brief summary, and what student likes most or the lessons they learn from their selected works. After the report, he/she answers one or more questions from the teacher or the class. Thirdly, the teacher can group three or four students who have read the same book into a discussion group. In these groups, students can prepare an oral book report or a written review to present to others in the class. These activities can give students a good chance to share their viewpoints and also help them improve their speaking, communicating and writing skills. Smith (1988, p.277) notes that there is evidence that "writing is one way of promoting engagement with a text, which leads to better comprehension." Last but not least, the reading teacher definitely needs to keep track of students' reading, their progress or any arising problems and guide students how to get the most out of extensive reading. Her frequent comments on students' reading journals seemed to be a good encouragement. Also, rewards can be given to the students for the quantity and the quality of reading they do. This can serve as the motivation to keep students excited about reading and realize their full reading potential.

For the students' claim of vocabulary hinders their understanding and uninteresting texts, it is the authors' suggestions as follows: In order to deal with this issue, it is essential that teachers and students should make use of simplified texts. Obviously, one good choice of simplified texts is Graded Readers with a number of interesting, well-written texts and with controlled vocabulary and grammar, which can match students' proficiency levels. Fortunately, these sources of materials are popular and easy to get with many interesting titles from Cambridge, Oxford, or Longman. Even though Graded Readers serve as a good source for our extensive reading, other types of texts might also be added, such as newspaper articles, advertisements, and recipes, all readily available from the Internet. This could provide learners with more choices for their interests of reading. A wider range in types of texts would broaden their knowledge and deepen their language skills. Moreover, right at the beginning of the course, the teacher needs to discuss with students about 
what types of genres and materials to focus on so that it is easier for her/him to monitor their reading. This could vary from year to year and should depend on students' needs, levels, and interests, as well as the availability of materials.

It seems that extensive reading fits in well with student-centered learning, which is highly encouraged by language teachers and educational authorities in Vietnam. Extensive reading promotes the basic features of student-centered learning as defined by Hedge (2000), including a focus on student experience, interest, and choice as well as a strong involvement by students in the decision-making process. It provides learners with a high exposure to English and open-ended tasks which can result in active and relevant learning. In conclusion, extensive reading is an effective way of teaching and learning in the Reading Comprehension subject because it makes learners more responsible and autonomous. In order to stimulate students' desire to read more, teachers of reading subject need to be highly flexible and elaborate in incorporating extensive reading into their lessons and designing a variety of tasks to ensure both effectiveness and learners' interest. Obviously, the job involves a lot of hard work and extensive reading does take time, thought, and effort of both teachers and students but the results might be well worth it. Therefore, it is highly recommended that extensive reading should be encouraged and implemented in the specific context of MSA.

\section{References}

Alderson, J.C. and Urquhart, A.H. (1984). Reading in a Foreign Language. London: Longman.

Bright, J.A. and McGregor, G.P. (1973). Teaching English as a Second Language. London: Longman Group Ltd.

Day, R.R. and Bamford, J. (1998). Extensive Reading in the second language classroom. Cambridge: Cambridge University Press.

Field, M.L. (2002). "Really Reading?” Guidelines, 24, 1, pp4-9.

Grabe, W. and Stoller, F. (2001). Teaching and Researching Reading. Harlow, UK: Longman.

Hedge, T. (2000). Teaching and Learning in the Language Classroom. Oxford: Oxford University Press.

Krashen, S.D. (1993). The Power of Reading: Insights from the Research. New York: Prentice Hall.

Le Thi Anh Phuong (2005). "Extensive Reading in a Vietnamese Context”, Teacher's Edition 17, pp.14-19.

Le Thi Huong Lan (2015). The Effects of Extensive Reading on 11th Graders' Vocabulary Development at Innovative Language Center. Hanoi: Hanoi University.

Mikulecky, B.S. (1990). A Short Course in Teaching Reading Skills. Oxford: Heinemann.

Nguyen Van Son (2002). “Using Extensive Reading to Improve Learners’ Autonomy”, CIE Journal, 23, 1. Hanoi: Hanoi University.

Siberstein, S. (1994). Techniques and Resources in Teaching Reading. New York: Oxford University Press.

Smith, C.B. (1988). "Reading Strategies and Extensive Reading in EFL Classes", RELC Journal,

30, 2, pp. 114-115.

Smith, F. (1985). Reading without Nonsense (2nd edition). New York: Teachers College Press. 